\title{
Prevalence of asymptomatic ST segment elevation in right precordial leads with right bundle branch block (Brugada-type ST shift) among the general Japanese population
}

M Furuhashi, K Uno, K Tsuchihashi, D Nagahara, M Hyakukoku, T Ohtomo, S Satoh, T Nishimiya, K Shimamoto

\begin{abstract}
Objective-To examine the modality and morbidity of asymptomatic ST segment elevation in leads V1 to V3 with right bundle branch block (Brugada-type ST shift).

Methods-8612 Japanese subjects (5987 men and 2625 women, mean age 49.2 years) who underwent a health check up in 1997 were investigated. Those with Brugada-type ST shift underwent the following further examinations over a two year period after the initial check up: ECG, echocardiogram, 24 hour Holter monitoring, treadmill exercise testing, signal averaged ECG, and slow kinetic sodium channel blocker loading test (cibenzoline, $1.4 \mathrm{mg} / \mathrm{kg}$ ).

Results-Asymptomatic Brugada-type ST shift was found in 12 of $8612(0.14 \%)$ subjects. Eleven of these 12 subjects were followed up. Follow up ECG exhibited persistent Brugada-type ST shift in seven of $11(63.6 \%)$ subjects. ST shift was transformed from a saddle back to a coved type in three subjects. None of the subjects had morphological abnormalities or abnormal tachyarrhythmias. Positive late potentials were found in seven of $11(63.6 \%)$ subjects. Augmentation of ST shift was shown by both submaximal exercise and drug administration in one of the 11 subjects $(9.1 \%)$.

Conclusions-Asymptomatic subjects with Brugada-type ST shift were not unusual, at a rate of $0.14 \%$ in the general Japanese population. Almost all of the subjects had some abnormalities in non-invasive secondary examinations. Additional and prospective studies are needed to confirm the clinical significance and the prognosis of asymptomatic Brugada-type ST shift.

(Heart 2001;86:161-166)
\end{abstract}

Keywords: Brugada syndrome; signal averaged electrocardiogram; sodium channel blocker; sudden death

Since Brugada and Brugada ${ }^{1}$ first described eight cases of characteristic ECG features consisting of right bundle branch block (RBBB) and persistent ST segment elevation in leads V1 to V3 (Brugada-type ST shift) associated with aborted cardiac sudden death without structural heart diseases, clinical evidence of a link between Brugada-type ST shift and cardiac sudden death has been accumulating. ${ }^{2-19}$ Because of increasing awareness of this evidence, a Brugada-type ST shift is being discovered incidentally in more and more asymptomatic subjects. Some recent reports describe Brugada-type ST shift recognised in asymptomatic subjects. ${ }^{515}$ However, the clinical significance of Brugada-type ST shift in asymptomatic subjects is unclear. Therefore, it is still not known whether a Brugada-type ST shift is a specific indicator of ventricular fibrillation or a life threatening sign of sudden cardiac death.

On the basis of these speculations, we investigated the prevalence of asymptomatic Brugada-type ST shift in the general Japanese population and performed secondary cardiovascular examinations focusing on latent myocardial involvement in the screened subjects.

\section{Methods}

STUDY POPULATION

The study population consisted of 8612 adult Japanese subjects (5987 men and 2625 women) ranging in age from 22-84 years (mean 49.2 years). All the subjects underwent medical examinations at the health care and medical health examination centre of Asahikawa Red Cross Hospital, Asahikawa, Japan, in 1997. Because the subjects were recruited mainly from patients undergoing a regular health check up requested by companies in which there is a preponderance of male workers, male subjects outnumbered female subjects in the study population. The age distribution of subjects is shown in fig 1 . The majority were in their 40s and 50s (6021 of $8612,69.9 \%)$. The initial screening medical check up consisted of standard 12 lead ECG, blood pressure measurements, haematological tests, and chest radiograph films. The subjects' personal medical histories such as syncope or near syncope, chest pain or discomfort, palpitation on rest or exertion, and their familial histories of sudden death, syncope, and heart diseases were also investigated by means of questionnaires.

\section{INITIAL ECG SCREENING}

The ECG abnormalities were double checked by following the Minnesota codes criteria and by two cardiologists experienced in recognising the following: bundle branch block, biventricular hypertrophy, ischaemic-like changes (for example, abnormal $\mathrm{Q}$ wave, $\mathrm{T}$ wave inversion, ST segment deviation), premature contraction, 


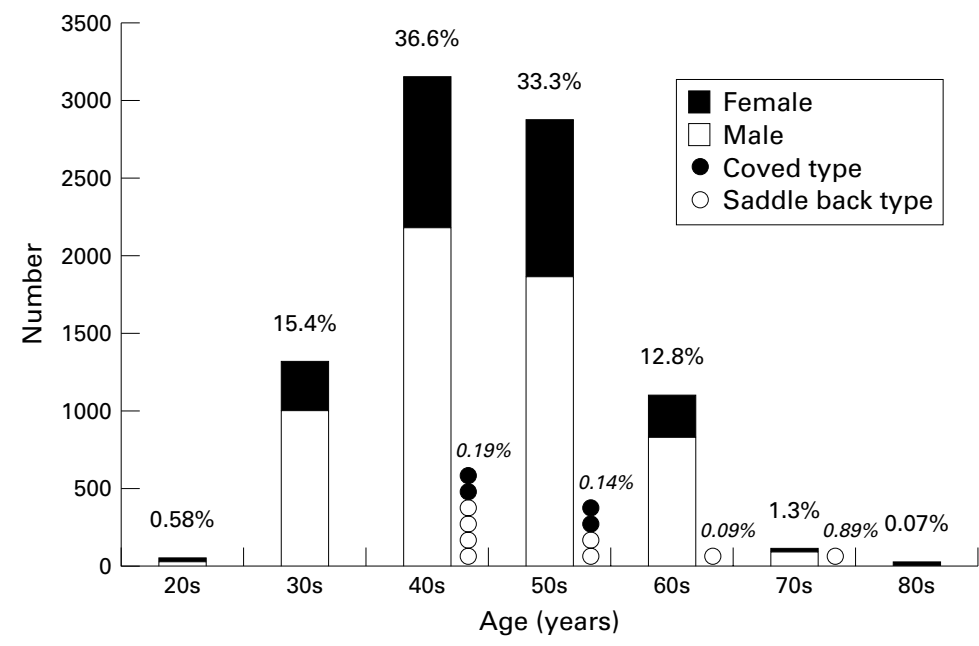

Figure 1 Bar graph showing age distribution of 8612 Fapanese subjects in this study. Open and closed bars represent the male and female population in each generation, respectively. The number at the top of each bar is the percentage of the total population. Open and closed circles represent the subjects with saddle back and coved type ST shift, respectively. The number at the top of each circle is the percentage of the population by generation.
FOLLOW UP AND SECONDARY EXAMINATIONS All of the patients with Brugada-type ST shift of the coved or saddle back type were asked again about their medical and familial histories in detail. After written informed consent was obtained from these subjects and permission to conduct the study was given by our hospital's ethics committee, follow up and secondary cardiovascular examinations including 12 lead ECG, echocardiogram, 24 hour Holter ambulatory monitoring (including heart rate variability analysis), symptom limited or submaximal graded treadmill exercise testing, and signal averaged ECG (SAECG) were performed in February 1999. ECG and SAECG recordings were also performed 10 minutes after intravenous administration of a slow kinetic sodium channel blocker (cibenzoline, $1.4 \mathrm{mg} / \mathrm{kg}$ ).

SAECGs were recorded by a Corazonix Predictor II (Corazonix Corp, Oklahoma USA). Signals from $200-300$ beats were accumulated. SAECG indices such as the total filtered QRS duration (f-QRS), the root mean square voltage of the $40 \mathrm{~ms}$ terminal portion of the QRS complex, and the low amplitude signal $<40 \mu \mathrm{V}$ of the terminal QRS complex were obtained. The positive late potential was defined by at least two of following criteria: $\mathrm{f}-\mathrm{QRS} \geqslant 114 \mathrm{~ms}$, root mean square $\leqslant 20 \mu \mathrm{V}$, and low amplitude signal $\geqslant 38 \mathrm{~ms}$.

gada-type ST shift was defined combination of RBBB and ST segment elevation (at least $0.1 \mathrm{mV}$ ) in right precordial leads (V1-V3) without showing apparently structural heart diseases. It was conventionally divided into a coved type and a saddle back type by the contour of ST segment elevation. ${ }^{20}$ The coved type ST segment elevation was defined as having at least one or more coved shapes in leads V1 to V3. The saddle back type was defined as having both at least one or more saddle back shapes and no coved shapes in V1 to V3. For example, Brugada-type ST shift with a coved shape in V1 and saddle back shapes in V2 and V3 was defined as a coved type ST segment elevation.

Table 1 Incidence of electrocardiographic abnormalities in studied subjects $(n=8612)$

\begin{tabular}{lrc}
\hline & Number & $\%$ \\
\hline Left ventricular hypertrophy & 1280 & 14.9 \\
Ischaemic-like changes & 392 & 4.6 \\
Conduction disturbances & 616 & 7.2 \\
RBBB & 318 & 3.7 \\
Incomplete & 170 & \\
Complete & 148 & \\
LBBB & 10 & 0.12 \\
AV conduction disturbances & 195 & 2.3 \\
First degree & 193 & \\
Second degree & 2 & \\
QRS axis deviation & 93 & 1.1 \\
Left & 75 & \\
Right & 18 & \\
Rhythm disturbances & 511 & 5.9 \\
Premature contractions & 249 & 2.9 \\
$\quad$ Atrial & 94 & \\
Ventricular & 155 & \\
Sinus arrhythmias & 221 & 2.6 \\
Bradycardia & 188 & \\
Tachycardia & 33 & \\
Atrial fibrillation & 41 & 0.48 \\
Others & & \\
WPW syndrome & 18 & 0.21 \\
\hline
\end{tabular}

$\mathrm{AV}$, atrioventricular; LBBB, left bundle branch block; RBBB, right bundle branch block; WPW, Wolff-Parkinson-White.

\section{STATISTICAL ANALYSIS}

All numeric variables are expressed as mean (SD). The difference between two independent or dependent variables was analysed by the unpaired Student's $t$ test or paired Student's $t$ test. A probability value of $p<0.05$ was considered significant.

\section{Results}

PREVALENCE OF BRUGADA-TYPE ST SHIFT

The incidence of ECG abnormalities is shown in table 1 . Left ventricular hypertrophy was the most common abnormality, observed in 1280 $(14.9 \%)$ of the subjects. Ischaemic-like changes were observed in $392(4.6 \%)$. RBBB was documented in $318(3.7 \%)$ subjects (incomplete, 170; complete, 148) and left bundle branch block in $10(0.12 \%)$. In the 318 subjects with RBBB, $39(0.45 \%$ of the total population) had ST segment elevation in V1 to V3 and 17 of these 39 subjects were classified as having coved or saddle back type contours. The other 22 subjects were excluded because the ST segment elevation was either the junctional (up sloping) type or impossible to classify. They had undergone a health check up at least once in the three years before the present study. Their ECGs were unchanged in shift was found at any health check up. Five of the 17 subjects with coved or saddle back type contours were also excluded from this study on the basis of their personal past histories and results of screening examinations: one with congenital heart disease (atrial septal defect), the present study, and no Brugada-type ST 


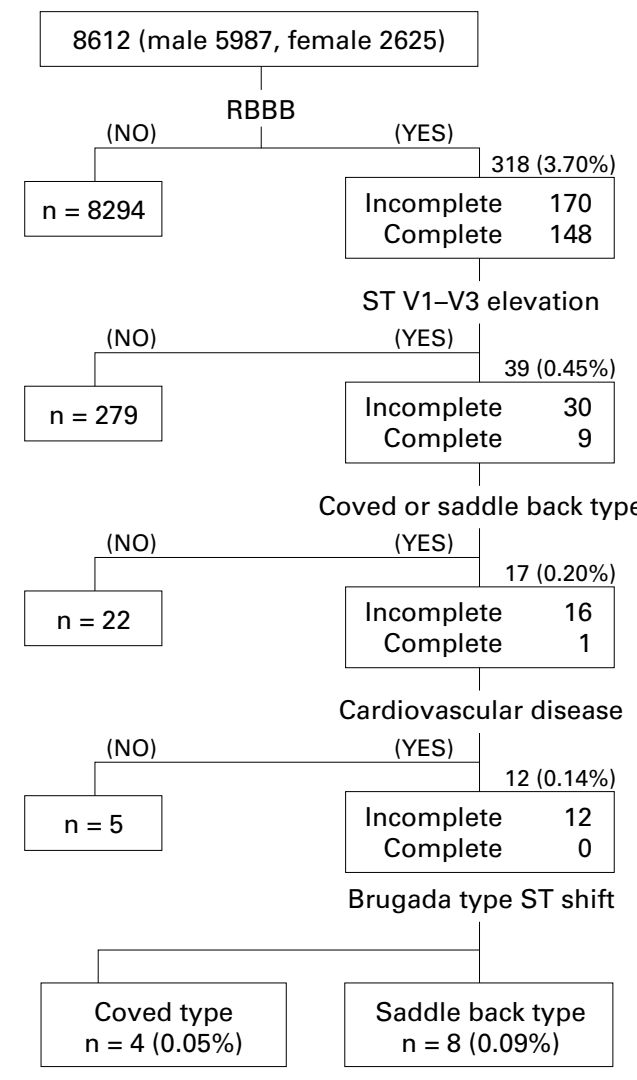

Figure 2 Diagnostic flow chart of Brugada-type ST shift in 8612 fapanese subjects. Values are the number (the percentage of the total population). RBBB; right bundle branch block.

three with hypertensive heart disease (left ventricular hypertrophy confirmed by echocardiogram), and one with first degree atrioventricular block (the PR interval of all patients was within normal limits in the original description of Brugada syndrome $\left.{ }^{1}\right)$. Finally, $12(0.14 \%)$ of the 8612 subjects ( 11 men and one woman; 42-72 years old; mean age 52.5 years) were considered to fulfil the diagnostic criteria of Brugada-type ST shift (fig 2). All of them had incomplete RBBB; the coved type contour was seen in four $(0.05 \%$ of the total population) and the saddle back type in eight $(0.09 \%)$. Six of this group were in their $40 \mathrm{~s}$ and four in their 50 s (fig 1 ). Between $0.1 \%$ and $0.2 \%$ of middle aged subjects in each decade had the Brugadatype ST shift.
FOLLOW UP EXAMINATIONS

Results of follow up and secondary cardiovascular examinations are summarised in table 2 . Eleven of the 12 patients with Brugada-type ST shift had follow up examinations. Although one subject (case 12) was not followed up medically because he had moved, we confirmed by telephone interview over a two year period that he was still alive. Serial transformations of ECG configuration in each type of ST shift are summarised in fig 3 and representative cases are shown in fig 4 .

Interviews with the subjects revealed that the 80 year old mother of one subject (case 5) had experienced several syncopal attacks but had not been closely investigated. The mother of another subject (case 6) had died suddenly at the age of 34 years. Other familial histories were hypertension in five subjects, apoplexy in two, and diabetes mellitus in one. None of the subjects had syncope or near syncope in relation to tachyarrhythmias.

\section{CARDIOVASCULAR EXAMINATIONS}

The results of echocardiographic studies, which were performed to rule out the possibility of right ventricular dysplasia, hypertrophic or dilated cardiomyopathy, or other forms of structural heart diseases, were normal in all 11 subjects. Twenty four hour Holter ambulatory ECG monitoring revealed premature ventricular contractions in five subjects, one of whom had 373 isolated monomorphic beats a day and the others had only a few. Neither pleomorphic or polymorphic ventricular tachycardias nor premature ventricular contractions were detected in any subjects. None of the subjects had fluctuation of ST segment elevation during 24 hour ST segment trend recordings. No abnormalities were found on heart rate variability in any of the 11 subjects.

During treadmill testing, exercise loading did not induce any tachyarrhythmias. Exercise normalised the ST segment elevation to the baseline level with heart rate increase in five of seven subjects with the persistent Brugadatype ST shift, while there was no change in one subject. In the other patient (case 10) with complete RBBB at the basal ECG, however, exercise augmented ST segment elevation with no arrhythmia or syncope.

Table 2 Follow up data of subjects with Brugada-type ST shift

\begin{tabular}{|c|c|c|c|c|c|c|c|c|c|c|c|c|c|}
\hline \multirow[b]{2}{*}{$\begin{array}{l}\text { Case } \\
\text { number }\end{array}$} & \multirow[b]{2}{*}{ Age/sex } & \multicolumn{3}{|l|}{$E C G$} & \multirow{2}{*}{$\frac{\text { Drug test }}{S T \text { shift }}$} & \multirow{2}{*}{$\frac{\text { Holter }}{\text { PVCs/day }}$} & \multirow{2}{*}{$\frac{\text { Treadmill }}{\text { ST shift }}$} & \multicolumn{3}{|c|}{ SAECG (control) } & \multicolumn{3}{|c|}{ SAECG (drug test) } \\
\hline & & $\begin{array}{l}\text { Initial } \\
\text { ST shift }\end{array}$ & $\begin{array}{l}\text { Follow up } \\
\text { QRS }\end{array}$ & ST shift & & & & $\begin{array}{c}f-Q R S \\
(m s)\end{array}$ & $\begin{array}{l}R M S \\
(\mu V)\end{array}$ & $\begin{array}{l}L A S \\
(m s)\end{array}$ & $\begin{array}{l}f-Q R S \\
(\mathrm{~ms})\end{array}$ & $\begin{array}{l}R M S \\
(\mu V)\end{array}$ & $\begin{array}{l}L A S \\
\text { (ms) }\end{array}$ \\
\hline 1 & $56 / M$ & Coved & Normal & & None & 46 & Unchanged & 127 & 20 & 32 & 136 & 14 & 50 \\
\hline 2 & $48 / \mathrm{M}$ & Coved & IRBBB & Coved & None & 0 & Normalised & 112 & 24 & 31 & 136 & 9 & 55 \\
\hline 3 & $56 / \mathrm{M}$ & Coved & IRBBB & Coved & None & 2 & Normalised & 108 & 55 & 29 & 122 & 69 & 27 \\
\hline 4 & $47 / \mathrm{M}$ & Saddle back & IRBBB & Coved & None & 1 & Normalised & 128 & 10 & 53 & 137 & 18 & 37 \\
\hline 5 & $52 / \mathrm{M}$ & Saddle back & IRBBB & Coved & None & 0 & Unchanged & 121 & 14 & 48 & 127 & 12 & 49 \\
\hline 6 & $57 / \mathrm{M}$ & Saddle back & IRBBB & Saddle back & None & 0 & Normalised & 117 & 32 & 26 & 129 & 19 & 46 \\
\hline 7 & $72 / \mathrm{F}$ & Saddle back & Normal & & None & 0 & Unchanged & 99 & 26 & 34 & 118 & 32 & 34 \\
\hline 8 & $43 / \mathrm{M}$ & Saddle back & Normal & & None & 53 & Unchanged & 108 & 17 & 42 & 124 & 15 & 46 \\
\hline 9 & $64 / \mathrm{M}$ & Saddle back & IRBBB & Saddle back & None & 373 & Normalised & 105 & 9 & 52 & 119 & 6 & 54 \\
\hline 10 & $42 / \mathrm{M}$ & Saddle back & CRBBB & Coved & Elevated & 0 & Elevated & 151 & 6 & 79 & 182 & 5 & 78 \\
\hline 11 & $44 / \mathrm{M}$ & Saddle back & Normal & & None & 0 & Unchanged & 109 & 18 & 39 & 122 & 9 & 50 \\
\hline 12 & $49 / \mathrm{M}$ & Coved & Not done & & & & & & & & & & \\
\hline
\end{tabular}

CRBBB, complete right bundle branch block; F, female; f-QRS, filtered QRS; IRBBB, incomplete right bundle branch block; LAS, low amplitude signal; M, male; PVC, premature ventricular contraction; RMS, root mean square; SAECG, signal averaged ECG. 


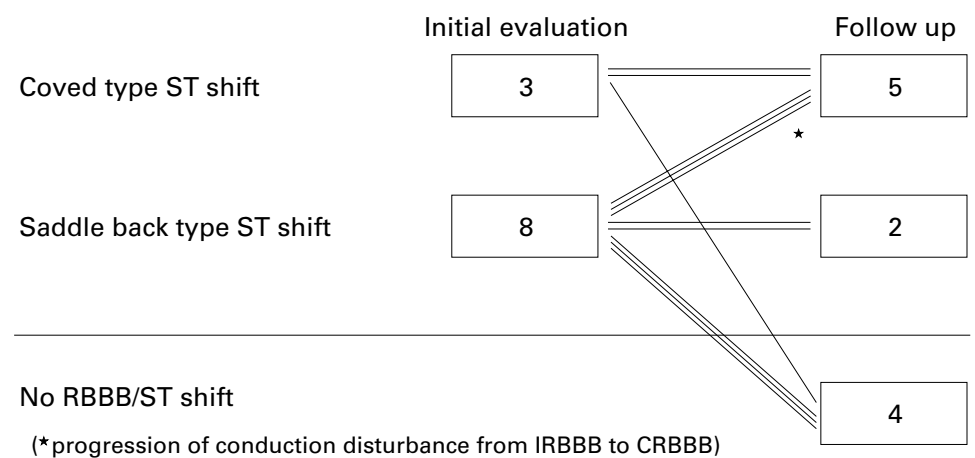

Figure 3 Serial transformation of Brugada-type ST shift in follow up ECG. Persistent ST shift was confirmed in seven (63.6\%) of 11 subjects followed up. However, Brugada-type $S T$ shift changed from the saddle back type into the coved type in three subjects.

Positive late potentials in the initial SAECG were detected in four (cases 4, 5, 9, and 10) of seven subjects with the persistent Brugadatype ST shift and even in three (cases 1,8 , and 11) of four subjects with the normalised ST segment elevation. Cibenzoline loading significantly enhanced f-QRS (116.7 (14.5), 131.7 (13.6), $\mathrm{p}<0.01$, before and after administration, respectively). Late potentials became more prominent after cibenzoline loading and were revealed in two patients (cases 2 and 6) with the persistent Brugada-type ST shift.

Interestingly, one patient (case 5) who showed transformation from saddle back to coved type ST segment elevation has experienced two episodes of syncope after drinking alcohol since undergoing medical health examinations in 1997 . He also has a familial history of syncope and a late potential on SAECG.

\section{Discussion}

In this study, we found an asymptomatic Brugada-type ST shift in $12(0.14 \%)$ of 8612 subjects and a persistent ST shift in seven

\section{A Coved type ST shift $\rightarrow$ No RBBB/ST shift}

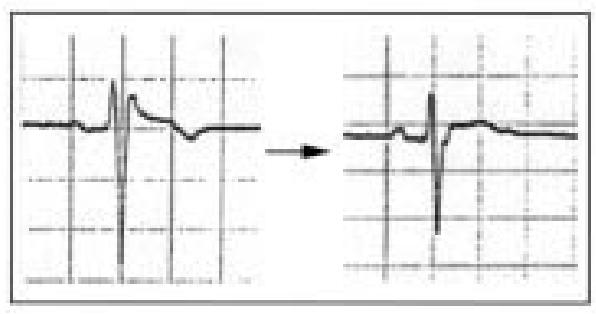

B Saddle back type ST shift $\rightarrow$ No RBBB/ST shift

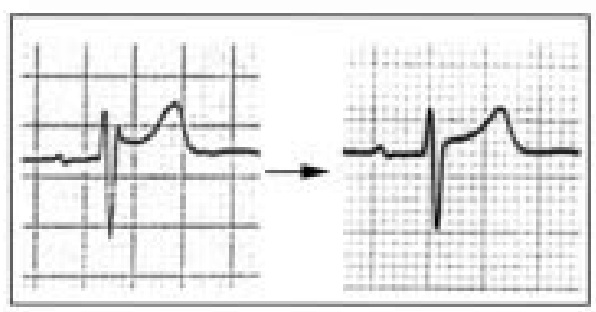

(63.6\%) of 11 subjects who underwent further examinations. None of the subjects showed echocardiographic abnormalities or tachyarrhythmias on Holter monitoring. Submaximal exercise and administration of an antiarrhythmic agent (cibenzoline $1.4 \mathrm{mg} / \mathrm{kg}$ ) augmented the ST shift in only one of 11 subjects.

REPRODUCIBILITY OF BRUGADA-TYPE ST SHIFT WITH OR WITHOUT UNDERLYING

CARDIOVASCULAR DISEASES

Brugada-type ST shift has been identified in relation with various cardiac and non-cardiac diseases, such as arrhythmogenic right ventricular cardiomyopathy, accidental hypothermia, and pulmonary hypertension. ${ }^{16} 172122$ None of the subjects with Brugada-type ST shift in the present study had ischaemia, electrolyte or metabolic disorders, pulmonary or inflammatory diseases, or abnormalities of the central or peripheral nervous system. Subjects with the Brugada-type ST shift were in their 40 s or older and the vast majority were men. It should be noted that the incidental finding of an asymptomatic Brugada-type ST shift appears to be common in middle aged men, especially those in their 40 s or 50 s, which is also the age when most patients with symptomatic Brugada syndrome are diagnosed. ${ }^{4}{ }^{18}$ Tohyou and colleagues ${ }^{5}$ reported that the frequency of coved type ST shift was $0.05 \%$ in healthy people. Viskin and associates ${ }^{15}$ also showed the estimated $95 \%$ confidence limits for the prevalence of a Brugada-type ST shift among healthy people to be less than $0.5 \%$. These figures are consistent with the findings of the present study.

The ST segment elevations reported by Brugada and Brugada ${ }^{1}$ were all of the coved type. Recently, it was recognised that the Brugada-type ST shift has variations. Atarashi and colleagues, ${ }^{3}$ reporting on 63 subjects with

C Saddle back type ST shift $\rightarrow$ coved type ST shift

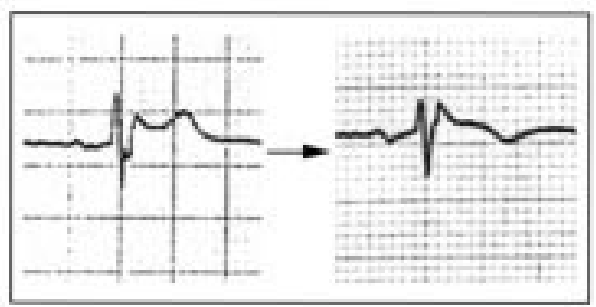

D Saddle back type ST shift $\rightarrow$ Coved type ST shift with QRS prolongation

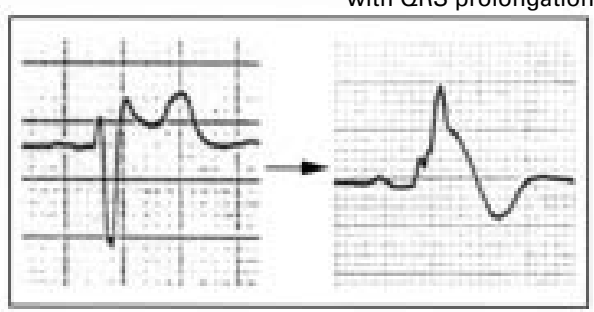

Figure 4 Representative cases of serial transformation. (A) Transformation of the coved type to no Brugada-type ST shift without right bundle branch block. (B) Transformation of the saddle back type to no Brugada-type ST shift without right bundle branch block. Transformation of the saddle back type to the coved type. (D) Transformation of the saddle back type to the coved type with prolonged QRS duration. 
Brugada-type ST shift recruited from 34 centres in Japan, noted that 34 of these 63 subjects were asymptomatic. Fourteen of the asymptomatic subjects showed the coved type and 20 the saddle back type ST elevation. Those authors concluded that the coved type ST segment elevation may be a warning sign of lethal ventricular arrhythmia, although this relation was not confirmed by other investigators. ${ }^{6}$ In the present study, ST segment elevation was transformed from the saddle back to the coved type in three of 11 subjects with Brugada-type ST shift (fig 3). We noted during follow up that the transformation of ST shift was not unusual. Therefore, careful follow up focusing on the reproducibility and persistence of the type of ST shift would be needed to understand the significance of the ST configuration in Brugada syndrome.

FLUCTUATION OF ST SEGMENT INDUCED BY DRUG ADMINISTRATION AND EXERCISE Fluctuation of ST segment elevation ${ }^{367}$ or transient normalisation ${ }^{8}$ seems to occur occasionally during follow up of Brugada syndrome. It has also been reported that sodium channel blockers, such as disopyramide, procainamide, ajmaline, flecainide, and pilsicainide, can unmask or exacerbate the Brugadatype ST shift. ${ }^{8-11} 19$ The use of antiarrhythmic agents is recommended as a possible diagnostic test in patients in whom the syndrome is suspected or in asymptomatic family members. ${ }^{4} 1219$ In the present study, we intravenously administrated cibenzoline, a slow kinetic sodium channel blocker, to the subjects with Brugada-type ST shift. However, Brugada-type ST shift was not discovered or exacerbated except in one subject (case 10) with the persistent Brugada-type ST shift. This subject had the saddle back type elevation with incomplete RBBB at the initial evaluation, but his QRS morphology and ST segment were transformed to the coved type with complete $\mathrm{RBBB}$ at follow up. The cibenzoline loading test in this subject revealed enhanced ST segment elevation with prolonged QRS duration. A slow kinetic sodium channel blocker was recently reported ${ }^{19}$ to reveal an augmented ST shift, proving that an unmasked ST shift can identify arrhythmic risk in an overt or concealed form of the Brugada syndrome. Hence, prospective follow up seems to be necessary when the ST segment is enhanced by sodium channel blocker loading because of a possibility of "high risk concealed Brugada syndrome".

Increasing the heart rate of one subject (case 10) augmented the ST segment elevation without normalisation during treadmill testing. ECG normalisation of the ST segment by increasing the heart rate has been reported in patients with Brugada syndrome. ${ }^{679}$ Recently, exercise induced ST segment elevation, which was frequently observed in V1 to V3, was reported in $65 \%$ of patients with arrhythmogenic right ventricular dysplasia. ${ }^{13}$ It has also been reported that arrhythmogenic right ventricular cardiomyopathy may underlie the cardiac manifestations in Brugada syndrome. ${ }^{14} 1617$ The echocardiogram of the subject (case 10) in the present study showed no positive findings suggestive of right ventricular dysplasia, and may be limited in its ability to detect morphological or mechanical abnormalities, especially in the early stage of arrhythmogenic right ventricular dysplasia.

HIGH RISK SUBJECTS WITH THE BRUGADA-TYPE ST SHIFT

According to a recent review, ${ }^{4} 22 \%$ of patients with Brugada syndrome have a familial history of syncope, documented ventricular fibrillation, or sudden death of suspected cardiac origin. Two subjects $(18 \%)$ in the present study fulfilled one of the above criteria. Atarashi and colleagues $^{3}$ divided patients with Brugada-type ST shift into three groups: a ventricular fibrillation group (type I) - patients with a history of documented ventricular fibrillation; a syncope group (type II) - those who had experienced a syncopal attack; and an asymptomatic group (type III) - those who had had neither ventricular fibrillation nor syncope. During the follow up period (452 (75) days), there were no recurrences of ventricular fibrillation, but two patients died suddenly at home. An episode of syncope was noted in one patient of the syncope group (type II). There were no cardiac events in the asymptomatic group (type III). Brugada and colleagues ${ }^{2}$ reported that six of 22 asymptomatic patients developed lethal symptoms (four sudden death, two aborted sudden death) during a mean follow up of 34 (30) months. Because the abnormalities in their ECGs were identified during screening after an episode of sudden death in a family member $(n=9)$ or during routine ECG $(n=13)$, the patients in that study may have a much higher risk than our subjects, biasing the comparison. Subjects identified by our study fell into the asymptomatic group (type III), although one (case 5) moved to the syncope group (type II) during two years of follow up because he had two episodes of syncope after drinking alcohol. It has been reported that the parasympathetic nervous system has an augmenting effect and the sympathetic nervous system an inhibitory effect on ventricular fibrillation induction of Brugada syndrome. ${ }^{6}$ Therefore, ventricular fibrillation episodes occur at times such as during sleep, rest, drinking, and urinating, but never during exercise.

It has been suggested that the onset of ventricular fibrillation is related to late $r$ ' waves and ST segment elevation but not to the frequency of premature ventricular contractions. ${ }^{6}$ Holter ECG monitoring in the present study revealed fewer than 400 premature ventricular contractions daily. Periodic variations in the ST segment and ventricular fibrillation were not observed. It has been reported that positive late potentials were observed in $81.5 \%$ of patients with Brugada syndrome. ${ }^{4}$ Kasanuki and colleagues ${ }^{6}$ also reported that late potentials were present even in the absence of $r^{\prime}$ waves in the right precordial leads. In our study, late potentials were positive in seven (63.6\%) of 11 patients, even in three of those who had no Brugada-type ST shift. Manolis and associates ${ }^{23}$ reported an incidence of false 
positive late potentials on SAECG of $16(30 \%)$ of 53 patients with incomplete RBBB compared with none of 19 subjects with a normal ECG. We also found an incidence of false positive late potentials of seven $(5.8 \%)$ of 120 patients with a normal ECG in our institution. Thus, although there were some diagnostic limitations, the prevalence of positive late potentials in the present study seems to have been higher.

\section{LIMITATIONS}

Since the follow up in this study was only two years, it would be premature to assess the prognostic value of Brugada-type ST shift in initially asymptomatic subjects. The fact that no ventricular arrhythmias were detected during the Holter monitoring or exercise testing does not prove or disprove the presence of the disease because even patients with proven Brugada syndrome and documented ventricular fibrillation generally do not have symptomatic arrhythmias between attacks. ${ }^{18}$ Obviously, further long term follow up is required.

The cibenzoline challenge test failed to augment ST segment elevation except in one subject in the present study. Other studies, however, have used different sodium channel blockers (mainly flecainide or ajmaline). There may be a difference between drugs.

In the present study, only one patient with Brugada-type ST shift accompanied by first degree atrioventricular block was excluded because the PR interval of all the patients was normal in the original description of the syndrome. ${ }^{1}$ However, the actual incidence of Brugada-type ST shift may be $0.15 \%$ (13 of 8612 ) rather than $0.14 \%$ (12 of 8612 ) because some patients with Brugada syndrome had infranodal conduction delay (prolonged $\mathrm{HV}$ interval). ${ }^{1}{ }^{10}$ Continued follow up, including of this one excluded patient, appears to be necessary.

\section{CONCLUSIONS}

Asymptomatic subjects with Brugada-type ST shift were not unusual in the studied population, comprising 12 of 8612 or $0.14 \%$ of the overall Japanese population. Their ECGs partly transformed from the saddle back type to the coved type of ST segment elevation or became normalised. Some abnormalities were found in almost all of the subjects during noninvasive secondary examinations. Additional and further prospective studies are needed to confirm the clinical significance and the prognosis of asymptomatic Brugada-type ST shift.
We would like to express special thanks to Ms. Keiko Hirama, Ms. Ritsuko Takahashi, and Ms. Ayako Marukawa, registered nurses at the Health Care and Medical Health Examination Centre of Asahikawa Red Cross Hospital, for their technical and secretarial assistance in this study.

1 Brugada P, Brugada J. Right bundle branch block, persistent ST segment elevation and sudden cardiac death: a distinct clinical and electrocardiographic syndrome. A multicenter report. f Am Coll Cardiol 1992;20:1391-6.

2 Brugada J, Brugada R, Brugada P. Right bundle-branch block and ST-segment elevation in leads V1 through V3. A marker for sudden death in patients without demonstrable structural heart disease. Circulation 1998;97:457-60.

3 Atarashi H, Ogawa S, Harumi K, et al. Characteristics of patients with right bundle branch block and ST-segment patients with right bundle branch block and ST-segment 581-3.

4 Alings M, Wilde A. "Brugada" syndrome. Clinical data and suggested pathophysiological mechanism. Circulation 1999; 99:666-73

5 Tohyou Y, Nakazawa K, Ozawa A, et al. [A survey in the incidence of right bundle brunch block with ST segment elevation among normal population.]. Ipn f Electrocardiol 1995;15:223-6. (In Japanese)

6 Kasanuki H, Ohnishi S, Ohtsuka M, et al. Idiopathic ventricular fibrillation induced with vagal activity in patients without obvious heart disease. Circulation 1997;95: $2277-85$.

7 Matsuo K, Shimizu W, Kurita T, et al. Dynamic changes of 12-lead electrocardiograms in a patient with Brugada syndrome. F Cardiovasc Electrophysiol 1998;9:508-12.

8 Brugada J, Brugada P. Further characterization of right bundle branch block, persistent ST-segment elevation, and sudden cardiac death. F Cardiovasc Electrophysiol 1997;8: 325-31.

9 Nademanee K, Veerakul G, Nimmannit S, et al. Arrhythmogenic marker for the sudden unexplained death mogenic marker for the sudden unexplained death
syndrome in Thai men. Circulation 1997;96:2595-600.

10 Miyazaki T, Mitamura H, Miyoshi S, et al. Autonomic and antiarrhythmic drug modulation of ST segment elevation in patients with Brugada syndrome. $\mathcal{A}$ Am Coll Cardiol 1996;27:1061-70

11 Fujiki A, Usui M, Nagasawa $H$, et al. ST segment elevation in the right precordial leads induced with class IC antiarrhythmic drugs: insight into the mechanism of Brugada syndrome. If Cardiovasc Electrophysiol 1999;10: 214-8.

12 Antzelevitch C. The Brugada syndrome. 7 Cardiovasc Electrophysiol 1998;9:513-6.

13 Toyofuku M, Takaki H, Sunagawa K, et al. Exercise-induced ST elevation in patients with arrhythmogenic right ventricular dysplasia. 7 Electrocardiol 1999;32:1-5.

14 Martini B, Nava A, Thiene G, et al. Ventricular fibrillation without apparent heart disease: Description of six cases. without apparent heart disease:

15 Viskin S, Fish R, Eldar M, et al. Prevalence of the Brugada sign in idiopathic ventricular fibrillation and healthy controls. Heart 2000;84:31-6.

16 Corrado D, Nava A, Buja GF, et al. Familial cardiomyopathy underlies syndrome of right bundle branch block, ST segment elevation and sudden death. F Am Coll Cardiol 1996; 27:443-8

17 Tada H, Aihara N, Ohe T, et al. Arrhythmogenic right ventricular cardiomyopathy underlies syndrome of right bundle branch block, ST-segment elevation, and sudden death. Am f Cardiol 1998;81:519-22.

18 Viskin S, Belhassen B. Polymorphic ventricular tachyarrhythmias in the absence of organic heart disease. Classification, differential diagnosis and implications for therapy. Prog Cardiovasc Dis 1998;41:17-34.

19 Brugada R, Brugada J, Antzelevitch C, et al. Sodium channel blockers identify risk for sudden death in patients with nT-segment elevation and right bundle branch block but structurally normal heart. Circulation 2000;101:510-5.

20 Goldberger AL. Myocardial infarction. Electrocardiographic differential diagnosis. 4th ed. Chicago: Mosby Year Book, 1991:200

21 Gussak I, Bjerregaad P, Egan TM, et al. ECG phenomenon called the J wave. History, pathophysiology, and clinical significance. F Electrocardiol 1995;28:49-58.

22 Hurst JW. Naming of the waves in ECG, with a brief account of their genesis. Circulation 1998;98:1937-42.

23 Manolis AS, Chiladakis JA, Malakos JS, et al. Abnormal signal-averaged electrocardiograms in patients with incomplete right bundle-branch block. Clin Cardiol 1997;20:1722 . 